\title{
Viewpoint
}

\section{Alzheimer's disease in the United Kingdom: developing patient and carer support strategies to encourage care in the community}

\author{
R Hunter, L McGill, N Bosanquet, N Johnson
}

Research and Development

Directorate, Greater Glasgow Community and Mental Health Services Trust, Gartnavel Royal Hospital, Glasgow $\mathrm{R}$ Hunter, director

Merton and Sutton Community Trust, Carshalton, Surrey L McGill, director

Health Policy Unit, Imperial College School of Medicine at St.Mary's, London $\mathrm{N}$ Bosanquet, professor of health policy

Health Economics Research Group, Cambridge Pharma Consultancy Ltd, Cambridge

N Johnson, principal

Correspondence to: Dr $\mathrm{N}$ Johnson, Health Economics Research Group, Cambridge Pharma Consultancy, 1 Quayside, Bridge Street, Cambridge CB5 8AB, UK.

Accepted for publication 30 June 1997

\section{Abstract}

Alzheimer's disease is a growing challenge for care providers and purchasers. With the shift away from the provision of long term institutional care in most developed countries, there is a growing tendency for patients with Alzheimer's disease to be cared for at home. In the United Kingdom, this change of direction contrasts with the policies of the 1980 s and 90 s which focused more attention on controlling costs than on assessment of the needs of the patient and carer and patient management. In recent years, the resources available for management of Alzheimer's disease have focused on institutional care, coupled with drug treatment to control difficult behaviour as the disease progresses. For these reasons, the current system has led to crisis management rather than preventive support-that is, long term care for a few rather than assistance in the home before the crises occur and institutional care is needed. Despite recent innovations in the care of patients with Alzheimer's disease, the nature of the support that patients and carers receive is poorly defined and sometimes inadequate. As a result of the shift towards care in the community, the informal carer occupies an increasingly central role in the care of these patients and the issue of how the best quality of care may be defined and delivered is an issue which is now ripe for review. The objective of this paper is to redefine the type of support that patients and carers should receive so that the disease can be managed more effectively in the community. The needs of patients with Alzheimer's disease and their carers are many and this should be taken into account in defining the quality and structure of healthcare support. This paper shows how new initiatives, combined with recently available symptomatic drug treatment, can allow patients with Alzheimer's disease to be maintained at home for longer. This will have the dual impact of raising the quality of care for patients and improving the quality of life for their carers. Moreover, maintaining patients in a home environment will tend to limit public and private expenditure on institutional care due to a possible delay in the need for it.

(Quality in Health Care 1997;6:146-152)

Keywords: Alzheimer's disease; community care; new initiatives

\section{Introduction}

With the continuing rise in the number of elderly people in developed populations, the overall burden of Alzheimer's disease will grow in most western countries. Much of the burden will fall on to the community as the provision of long term institutional care is targeted at those with greatest immediate need. As a result, the deployment of resources to community and institutional care will be a major challenge for the National Health Service (NHS) and social services in the coming years. Based on the United Kingdom experience, the aim of this paper is to help refocus attention on defining the ways in which Alzheimer's disease can be managed effectively in the community, so improving quality of life for patient and carer and possibly reducing public expenditure.

We begin by outlining the social and economic burden that Alzheimer's disease represents. This disease is the most common form of dementia and is associated with reduced life expectancy and considerable morbidity. Also, the economic burden on the NHS and social services is substantial, particularly in relation to institutional care which is more frequent as the disease progresses. The practical and financial burden has shifted to informal carers who now occupy a central role in maintaining patients in the community. Despite this, carers are not always well equipped to cope with the difficulties the disease creates. Unless informal carers are better able to carry this burden in the community, the cost to the NHS and social services will escalate beyond control.

The paper then considers new initiatives in care provision which will help to maintain patients with Alzheimer's disease at home. These show the attention that is being focused 
Total $=320000$ with advanced cognitive deficit

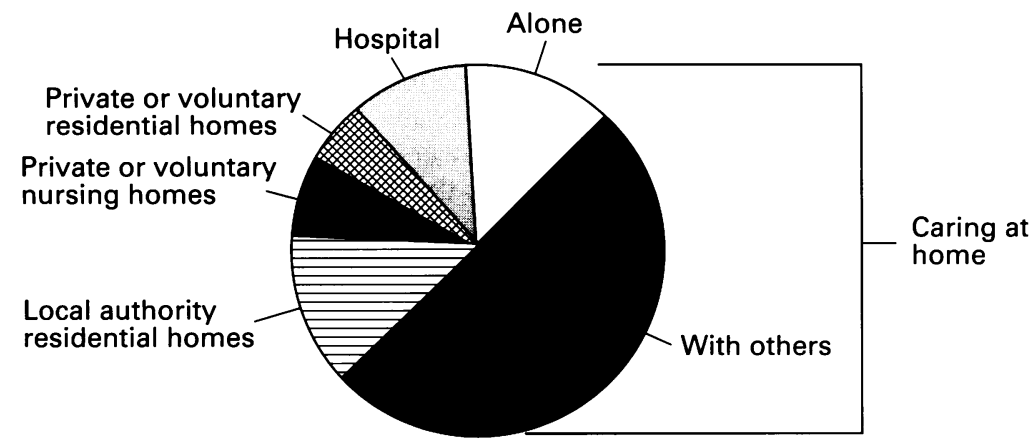

Figure 1 Most patients with Alzheimer's disease are cared for at home.

on the disease in different parts of the United Kingdom but the initiatives represent only a first step. Integration of these various initiatives into care packages that are tailored to specific situations of patients and carers still need to be developed and this should be the future objective for the NHS and social services in this disease area.

\section{Alzheimer's disease: epidemiology and changing patterns of care}

Alzheimer's disease affects $50 \%$ to $75 \%$ of people with dementia ${ }^{1}$ and the incidence is strongly correlated with increasing age. ${ }^{2} \mathrm{Al}-$ though estimates show that the prevalence of all dementia in the United Kingdom is $0.1 \%$ for people aged $40-65^{1}$ rates increase to around $2 \%$ for the age group 65-70, and dementia affects up to $20 \%$ of people over the age of 70 ( $18.5 \%$ for men, $22.8 \%$ for women). ${ }^{23}$ The prevalence of the disease tends to be consistent across European countries, ${ }^{4}$ and over a third of people who reach the age of 90 can expect to be affected by this incapacitating disease.

The Alzheimer's Disease Society estimates that there are currently about 621000 people over 65 with dementia in the United Kingdom, about 466000 of whom will have Alzheimer's disease. As in most western countries, the number of people in this age group is expected to rise considerably over the next few decades, ${ }^{5}$ which will have major economic and social implications for the providers and purchasers of health and social services. Informal carers are increasingly expected to bear most of the informal care burden and they will also be greatly affected.

\section{CARE IN THE COMMUNITY}

Care in the community is now the byword for care of elderly people and long term mentally ill. In fact the term community care is something of a misnomer; it encourages an image of care by the state. In reality, its meaning has changed from care in the community to care by the community, as the burden of primary care and community based services increasingly falls upon informal carers (usually close family and friends).

In the United Kingdom, more than $60 \%$ of elderly people with advanced cognitive deficits live in their homes in the community, and about a fifth of these live alone ${ }^{6}$ (fig 1); in fact this is most likely to be an underestimate as mild cases of dementia were not included in this particular study. This represents a substantial burden for carers who frequently cope with limited professional support.

It is estimated that informal carers save the state between $£ 15$ and $£ 24$ billion per year by supporting dependants who would otherwise need institutional care. ${ }^{8}$

As is the case in many other countries, the United Kingdom has had a tradition of long term inpatient care, but there is now a move away from permanent care provided by the NHS and local authorities. In the early 1980s, the government encouraged the use of private care beds by permitting social security to fund private nursing home and residential care. Between 1980 and 1990 this policy produced an increase in the number of elderly and chronically ill people living in private residential care beds of over $300 \%,{ }^{9}$ and put a major burden on public spending. To reduce the growing cost burden the 1990 NHS and Community Care Act was introduced which discouraged admission to hospital and residential care until all other options have been explored; as a result the provision of care was shifted to patients and their families.

"Community care has changed from meaning care in the community to care by the community."

With this change of policy, the number of long term beds has been reduced by the NHS and local authorities (fig 2 ).${ }^{10}$ At the same time there has been an increase in the number of beds contracted from the private sector and this trend is likely to continue in the future. However, this policy has been introduced with no apparent cost shifting between health and social services: local authority provision is means tested and patients now bear the initial burden until their personal funds fall below a certain threshold. These changes threaten to create a care deficit with many more frail elderly people living in the community and a consequent rise in the pressure on informal carers - that is, the patient's family and friends.

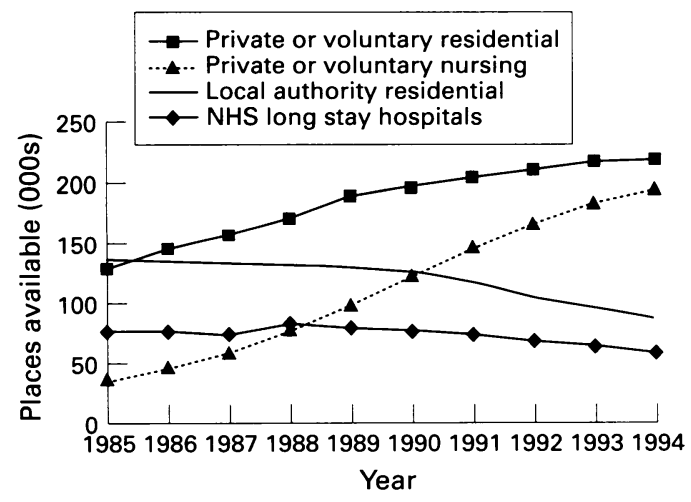

Figure 2 Provision of beds for the elderly and disabled has moved to the private sector. 
Table 1 Where patients with Alzheimer's disease live

\begin{tabular}{lccc}
\hline & \multicolumn{2}{c}{ Total cognitively impaired } & \\
\cline { 2 - 3 } Situation/service package & $(n)$ & $(\%)$ & $\begin{array}{l}\text { Mean OPCS } \\
\text { score }\end{array}$ \\
\hline At home alone & 42826 & 13 & 8.47 \\
At home with others & 159659 & 50 & 9.48 \\
Local authority homes & 45191 & 14 & 9.60 \\
Private or voluntary residential homes & 15134 & 5 & 9.18 \\
Private or voluntary nursing homes & 23297 & 7 & 9.51 \\
Hospital & 33750 & 11 & 9.83 \\
\hline
\end{tabular}

* The Office of Population Censuses and Surveys (OPCS) uses its own disability index to measure level of cognitive impairment: an increasing number reflects a decrease in cognitive function. Source: Schneider et $a l,{ }^{\dagger}$ based on OPCS data from 1985.

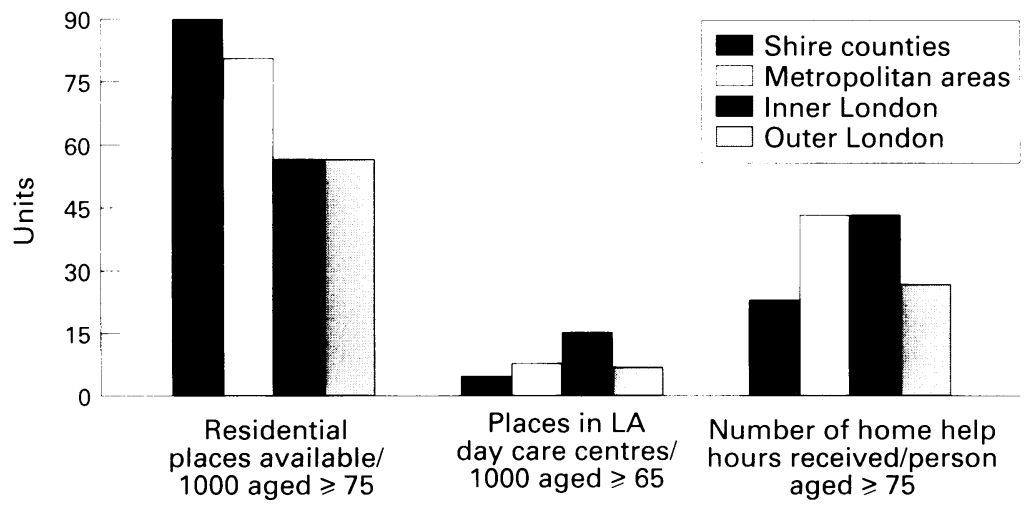

Figure 3 There is considerable variation in local availability of services.

SEVERITY OF ALZHEIMER'S DISEASE AND SETTING OF CARE

The relation between level of cognitive impairment and residential care is such that only the more severe cases of Alzheimer's disease are likely to be institutionalised. The table summarises the results of a United Kingdom survey of care for Alzheimer's disease ${ }^{6}$ and shows that patients with the best cognitive function (lower values of the dementia scoring system of the Office of Populations, Censuses and Surveys) are more independent and live at home. The highest scores (most impaired) are for those living in hospital.

As with all care in the community the availability of services for Alzheimer's disease represents one of the biggest issues facing patients and carers. A recent survey in Dundee concluded that the presence of dementia was associated with a high level of unmet need for mainstream medical services and domiciliary support. ${ }^{11}$ Overall, there is substantial local variation in the type and amount of community and long term care provided across the United Kingdom, ${ }^{12}$ and this applies to both community and residential care ${ }^{13}$ (fig 3 ).

The strong focus of the NHS and social services on the more severe cases of Alzheimer's disease is understandable: resources are limited and the needs become clearest as the severity of Alzheimer's disease increases. Until recently there was no reason for the patient to present earlier because of the relative lack of treatment for mild or moderate cases. General practitioners were also reluctant to diagnose Alzheimer's disease due to previous lack of treatment alternatives. Because of missed diagnosis, there is still a lack of recognition of Alzheimer's disease in its early stages.
These factors have so far limited the extent to which patients with Alzheimer's disease and their carers have been supported by health and social systems. The same is true for some other European countries. In Italy, for instance, a study reported an average of 22 months between the onset of symptoms and the first presentation to the general practitioner (GP). ${ }^{1+}$

\section{Financial cost and funding of care}

Disability arising from the progressive decline in cognitive function eventually limits normal functioning. Because of this, the care needed for the management of the disease targets two areas: the medical aspect (need for medical assessment and diagnosis, medication, etc) and the social aspect of the disease (provision of meals on wheels in the community, home care, etc).

Drug expenditure on Alzheimer's disease is clearly reported to be low. ${ }^{15}$ As with many disease areas, studies have shown that long term care in institutions or in the community (formal and informal care) is the most costly component and that drug treatment constitutes only a small part of the care costs for patients with Alzheimer's disease. ${ }^{16} 17$ Two United Kingdom studies performed in the past 10 years estimated the total annual costs of Alzheimer's disease (including direct and indirect costs) at $£ 1039$ million and $£ 4684$ million. ${ }^{6}{ }^{17}$ This is in the same region of cost as other chronic diseases in the United Kingdom-for example, Davies and Drummond found that the cost of schizophrenia was $£ 1600$ million. ${ }^{18}$ On the basis of two studies conducted in the United States, total costs for arthritis and epilepsy were estimated at $£ 1200$ million and $£ 500$ million respectively, for the United Kingdom (1989-90 figures). ${ }^{1020}$

The two United Kingdom studies ${ }^{17}$ used different approaches to costing Alzheimer's disease but the distribution of the costs was similar with both studies highlighting the cost burden of residential care. For example, Gray and Fenn ${ }^{17}$ found that $65 \%$ of total care cost (excluding informal care) is attributed to residential or nursing home care, and $25 \%$ to hospital based care.

Studies have shown that the cost of services for patients with dementia varies according to the severity of the disease - for example, the costs of community care for moderate dementia were twice those of mild dementia in Canada. ${ }^{16}$ In view of the shift towards care in the community it is particularly noteworthy that the need for informal care more than doubles for patients with severe dementia compared with mild dementia. ${ }^{21}$ This relation between costs and severity has been supported by studies in other European countries, ${ }^{22}{ }_{23}$ most of which use the mini mental state examination (MMSE) to measure cognitive dysfunction.

FRAGMENTATION IN THE FUNDING OF CARE

The funding of medical and social aspects of Alzheimer's disease is characterised by a considerable fragmentation and a multiplicity of purchasers and providers (fig 4). Division between health authorities and the local 


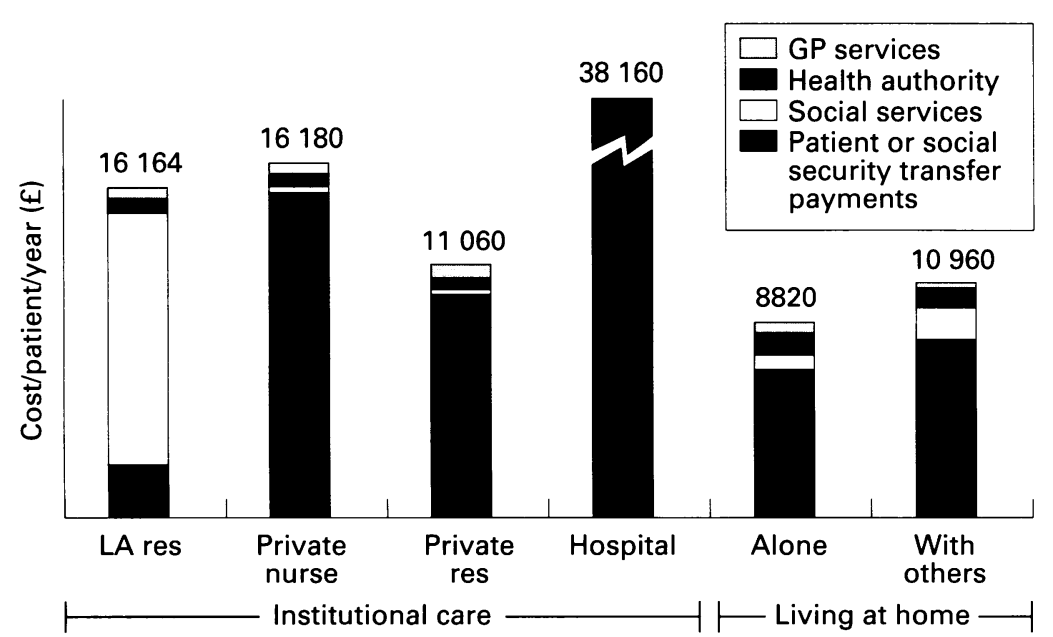

Figure 4 Cost of managing patients with Alzheimer's disease varies considerably by setting.

authorities has created problems in the past and is inconsistently handled across the United Kingdom. Historically, it has been much easier to fund residential care when patients become severely disabled enough to warrant intervention than to support many patients with milder disease at home.

Health and local authorities are responsible for identifying and meeting their population's care needs. As well as the funding of social services (which provides meals on wheels, etc), the local authorities now contract with different service agencies to provide residential, nursing, and home care to their population. ${ }^{624}$

The shift of funding from national to local level was not implemented without difficulties. Local authorities' inability to raise local taxation meant that in some cases the demand for services could not and cannot be met. As a result, the financial burden of care is increasingly being born by the carer. ${ }^{12526}$

\section{CONTRIBUTIONS BY PATIENTS AND CARERS}

There is international evidence of the substantial financial, social, and psychological burden on informal carers. ${ }^{25-28}$ In the United Kingdom, the patient's contribution to institutional care is subject to financial means testing ${ }^{29}$ (patients outside local homes may, however, receive a living allowance $\left.{ }^{30}\right)$. As well as institutional care, patient contributions are also required for certain forms of community care-for example,

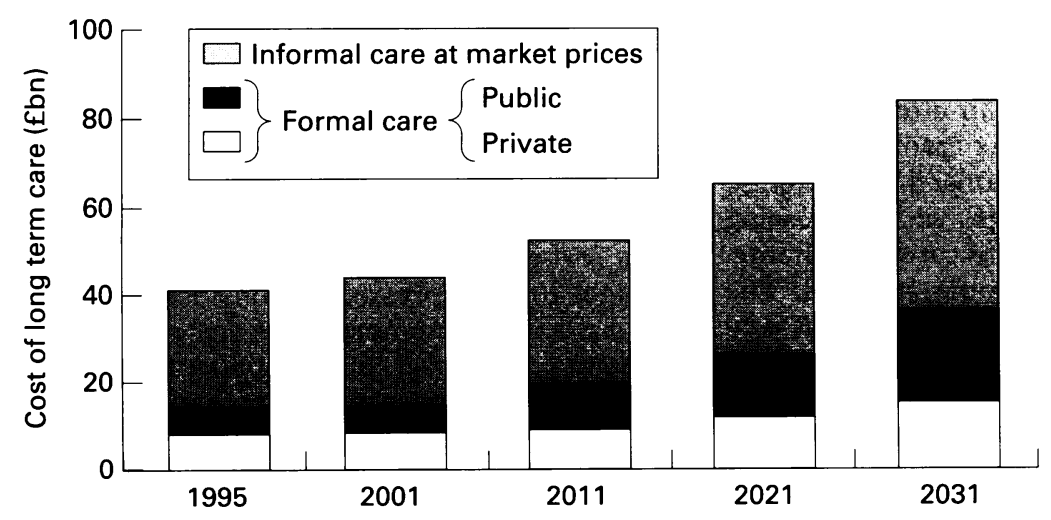

Figure 5 The cost of informal care will probably increase. day and domiciliary care, home help, and provision of meals.

The patient or his family bears about $50 \%$ of the total cost of care for advanced cognitive impairment; the burden is about $75 \%$ for those living in a private household. ${ }^{6}$ These figures are supported by Gray and Fenn ${ }^{17}$ who found that $66 \%$ of direct care costs are covered by patients and informal carers. The total costs of dementia care, together with the proportion paid by informal carers, will probably rise in line with those for elderly people in general over the coming 30 years (fig 5 ).

This is to say nothing of the healthcare costs for the carer themselves. This may not be borne entirely in terms of direct medical care costs but there are strong signals that informal care givers pay a high price in terms of their own health for providing this service to their loved ones. ${ }^{31}$ Care givers are more likely to have health problems and to be taking medications than non-care givers. Care givers are stressed, lack sleep, are fatigued, and have somatic complaints, anxiety, and depression. ${ }^{32}$ Stress, depression, and immunosuppression are three times more common in care providers than in non-care providers. ${ }^{33}$ Psychotropic drugs are used by $30 \%$ of care givers, twice as much as by elderly non-care givers. Spouse care givers are most likely to take antianxiety drugs, care givers with financial problems use anxiolytic and hypnotic drugs, and care givers who feel stressed and lacking in support are most likely to use antidepressant drugs. If the patient is depressed, then it is more likely that the care giver will become depressed. ${ }^{32}$

The fragmentation of funding and provision of services between health and local authorities may increase financial accountability for each agency but it creates difficulties for the patient and carer. It diffuses the responsibility for providing and funding patient care and the net result is a greater burden on the informal carer than might otherwise be necessary.

\section{New initiatives in care provision}

At a time of shifting care patterns and priorities, what should patients with Alzheimer's disease and their families expect from health and social support systems? In an attempt to assess the ways in which better care can be provided experimental projects have recently been started in the United Kingdom. For example, a major United Kingdom housing association challenged the view that sheltered housing is not appropriate for people with dementia, by showing that these patients can do well in supported housing. ${ }^{34}$ This kind of study can help change perceptions of how to provide care for those with dementia, particularly with regard to their environment and interaction with other people.

There is no doubt that the various situations that patients find themselves in make the provision of a customised care package a necessity. By improving the assessment of care needs, the care for patients with Alzheimer's disease can be better tailored, so improving the overall quality of care for carers and for the patients themselves. There have been many 
attempts to do this. For example the Dementia Services Development Centre at Stirling University has developed CarenapD, ${ }^{35}$ the care needs assessment pack for dementia. CarenapD, which is currently being assessed at various sites in Scotland, is a tool to estimate the care needs of people with dementia and their carers.

In the south of England a community hospital is assessing care needs at an early stage of the disease. ${ }^{36}$ This hospital is developing an early intervention programme in which the lifestyle of individual patients with Alzheimer's disease is adapted to take account of handicap at an early stage in the illness. The aim of this scheme is to help preserve cognitive and functional skills for as long as possible, and to help patients to adjust to the progress of their disease. Each patient has his own "portfolio of care" which forms an effective system of providing good quality, individualised care which can be delivered by a wide range of helpers in various care settings.

Because of the central role of informal carers in the daily life of most patients with Alzheimer's disease, meeting the carer's needs is also an important determinant of the quality of care. The South Devon Carers Consortium is implementing a project ${ }^{37}$ which aims to raise awareness of the needs of carers within the primary healthcare team, and develop networks and services to meet these needs. The Merton and Sutton Community NHS Trust ${ }^{38}$ is also investigating this. As well as identification of carers, members of the primary healthcare teams aim to refer carers to specifically designed health promotion courses.

There are also examples of training initiatives directed at the carer. "Training and liaison for carers and care workers" ${ }^{\prime 39}$ is a project being developed by the Preston Hall Hospital in Maidstone. Information is provided for carers about health related issues, as well as courses in nursing and physiotherapy skills.

There are also many initiatives to improve staff training; for example, the Bradford Dementia Centre offers courses in "dementia mapping", involving practical, teaching, and interpersonal skills.

The effective implementation of care strategies is also an important dimension of quality in care and in some areas, local and health authorities are starting to work together to achieve this. Cambridge and Huntingdon Health Authority has drawn up a policy framework to clarify the respective roles of the local authority and the NHS in an attempt to stop patients "falling between the cracks" in provision of care. As in other regions, they recognise a hierarchy of care settings, with increasing specialisation and intensity of care: own home, residential home, nursing home, hospital. The level of disability (mental and physical) as well as the burden on the carer determine the need; when the medical needs of a patient increase, they move up the scale ${ }^{30}$ and institutional care is more likely. In other words, admission to long term care is on the basis of defined need, rather than being dictated by the level of service.
For some health and local authorities, working together also means pooling budgets. The Crewkern carer project ${ }^{40}$ and the Bridgwater carers support scheme, ${ }^{41}$ supported by both the Carers National Association and the Red Cross, are two examples of carers' projects which receive financial support from both the health and social services. Each of these projects is based in primary care and involves about 40 general practitioners; they promote a range of services aimed at supporting the carer, including advice and information, organisation of carers support groups, supportive listening, and referrals for patients and carers.

RECENT DEVELOPMENTS IN DRUG THERAPY

The use of drug treatment in Alzheimer's disease is currently limited. Until recently there was no effective treatment to control the symptoms of the disease and, rather than treat the patient, drugs were used primarily to control difficult behaviour or limit depression which affects up to $30 \%$ of patients with Alzheimer's disease. ${ }^{42}$ Because of this, neuroleptic and antidepressant drugs have been the mainstay of management by drug treatment to date.

Tacrine (an acetylcholinesterase inhibitor) was the first symptomatic drug for Alzheimer's disease to be launched, although safety concerns meant that it was not made available in the United Kingdom. More recently donepezil (Aricept), a new once daily acetylcholinesterase inhibitor developed for the symptomatic treatment of mild to moderately severe Alzheimer's disease, has been made available and is the only approved treatment for Alzheimer's disease in the United Kingdom. Well designed controlled clinical trials have proved the efficacy of Aricept in improving both cognitive function and global function of the patient. ${ }^{44}$ The safety and tolerability profiles of this agent suggest that it will be well accepted by patients, and easy for care givers to administer. Aricept will thus offer new opportunities for helping patients live independently for longer and for relieving the stress of carers. As drug treatment is now available, early diagnosis of Alzheimer's disease should become a greater priority.

OPPORTUNITIES AND AGENDA

Several new initiatives have the potential to improve the care that patients with Alzheimer's disease receive. Although this creates opportunities for better quality care, this cannot be achieved with current approaches to patient management, and a considerable shift of emphasis will be needed:

There will be a need for improved diagnostic accuracy, particularly at general practitioner (GP) level. A recent survey by the Alzheimer's Disease Society among 2000 carers $^{1}$ found that $30 \%$ of patients with dementia were first thought to be depressed or considered to have age associated memory disorder rather than dementia. Moreover, $60 \%$ of patients who presented with memory problems had no cognitive assessment or memory tests, yet these clearly aid detection of the disease. ${ }^{45}$

Patients must be identified by the healthcare system at an earlier stage of the disease than at 
present. With the advent of effective drug treatment the early diagnosis of Alzheimer's disease is important; treatment for early disease may delay the onset of symptoms and improve the quality of life of the patient and the carer. Early diagnosis may also rule out other causes of dementia which may be treatable and require different management. ${ }^{45}$ The introduction of brief, easily used screening tests ${ }^{46}$ deserves consideration as a first step during the over $75 \mathrm{~s}$ annual health check. Alternatively, the MMSE is widely used for cognitive assessment in both the United Kingdom and United States ${ }^{47}$ and has considerable value in the detection of progressive cognitive impairment. ${ }^{48}$

New care programmes carry a cost and purchasers of health care will be concerned about their potential budgetary impact. Health and social services will not necessarily bear the burden of cost associated with the use of a drug such as Aricept. Because it may delay the loss of cognitive function associated with Alzheimer's disease, ${ }^{49}$ Aricept is a drug which may reduce morbidity to such a degree that the need for institutional care is delayed without increasing life expectancy. In this situation the period for which this high cost element will be needed will be reduced or compressed ${ }^{50}$ resulting in a saving in resources.

As well as keeping the patient at home longer, improved cognitive and global function associated with drug treatment may also bring about a reduction in the numbers of hours of informal care required in the short term, and a reduction in the intensity or the amount of community support services-for example, less need for meals on wheels, fewer nurse visits, and reduced use of professional carers.

These kinds of savings have already been described with tacrine, which delayed entry into institutional care by up to nine months, and savings of $17 \%$ to $30 \%$ were reported. ${ }^{51}{ }^{52}$

\section{Conclusions}

The carer has a central and increasingly important role in the management of patients with Alzheimer's disease and this will increase in the future. For this to be sustainable, the provision of adequate professional support must be a part of any new contract between professional and informal care givers.

However, it is clear that the provision of quality care in a domestic or non-institutional setting cannot be achieved through the use of a "one size fits all" policy and the nature of good quality care has yet to be defined clearly. Fortunately, many valuable initiatives are being established which will help to overcome the problem of poor provision of services and coordination. These programmes would seem to complement drug treatment, which itself is likely to have an increased role in the next few years for patients with Alzheimer's disease. These tailored care packages can raise the quality of support available to both the patients and their carers, as each is an inseparable part of care in the community for Alzheimer's disease.
Although drug treatment has the potential for reducing the costs for local authorities, and to some degree the patient and carer, the purchase of drug treatment lies within the NHS. To encourage the appropriate use of drug treatment on the basis of needs of patients and carers, local and health authorities may need to pool budgets so that a flexible care package can be developed which is tailored to the specific needs of the patient. To avoid disparities in the delivery of care, the development of care protocols will be essential.

The development of medical guidelines to ensure best standard practice and accurate differential diagnosis would be a decisive step towards improved management of Alzheimer's disease. The new initiatives which are currently being developed in care provision in the United Kingdom are promising but need proper evaluation as they are developed further as an integrated approach that combines medical and social care. Below are initiatives of high priority.

(1) The primary and secondary care sectors need to develop shared care protocols if patients are not to fall between the cracks that exist between care providers.

(2) The routine annual check of the elderly (over 75s) in the United Kingdom is not designed to detect Alzheimer's disease, although there is no reason why simple cognitive assessments should not be included.

(3) Management guidelines and protocols will be needed to support clinicians (particularly GPs) in the recognition and treatment of patients with Alzheimer's disease. This is likely to have implications for the role of other professions in primary care, particularly nurses.

(4) There will be a need to exploit all aspects of care that are likely to enable patients to be cared for more successfully and for longer, at home.

It is clear that new approaches, from sheltered housing to new drug treatments, offer possibilities that were previously not available. No single approach will fit the needs of all patient-carer situations and a flexible, integrated approach to care provision and funding is likely to be the most successful. It is likely, however, that good community based care will be facilitated by specific Alzheimer drug treatments that are now becoming available.

The introduction of Aricept provides an opportunity to develop a more integrated pattern of care with a wider range of partners, as follows:

(1) Family doctors will not only be involved in prescribing but they will also be increasingly involved in providing and purchasing support services as fundholders. They will work more closely with colleagues-such as community psychiatric nurses as well as other community nurses.

(2) Respite care in nursing homes could provide considerable help to carers and patients at a much lower cost than permanent institutional care.

(3) Community trusts can develop innovative models of day service and local rehabilitation. 
There can also be new alliances between the public and private sectors to offer low cost support services to delay the need for institutional care. These should incorporate the emerging new health technologies that are being developed or have been recently introduced. The next few years could be a much more positive period in the development of dementia services in which there will be a tailored definition of what represents quality health and social support for the patient and carer, and more achievable aims through the use of innovative and flexible approaches to care and drug treatment.

We acknowledge sponsorship of the work by Pfizer Pharmaceuticals Group.

1 Alzheimer's Disease Society. Right from the start: primary health care and dementia. A report by the Alzheimer's Disease Society' on the experiences of GPs and carers of dementia diag nosis. London: ADS, July 1995.

2 Jorm AF, Korten AE, Henderson AS. The prevalence of dementia: a quantitative integration of the literature. Acto Psychiatr Scand 1987;76:465-79.

3 Melzer D, Hopkins S, Pencheon D, Brayne C, Williams R. Dementia. In: Stevens A, Raftery J, eds. Health care needs Dementia. In: Stevens A, Raftery J, eds. Health care needs
assessment. The epidemiologically based needs assessment assessment. The epidemiologically based needs assessment
reviezus. Vol 2. Oxford: Radcliffe Medical Press, 1994:305 revieas 40.

4 Rocca WA, Hofman A, Brayne C, et al. Frequency and distribution of Alzheimer's disease in Europe. A collaborative study of 1980-90 prevalence findings. Ann Neurol 1991;30 381-90.

5 United Nations. The sex and age distributions of the world populations. 1994 rev. New York: United Nations, 1994.

6 Schneider J, Kavanagh S, Knapp, M, Beecham J, Netten A Elderly people with advanced cognitive impairment in England: resource use and costs. Ageing and Societ 1993;13:27-50.

7 Kavanagh S, Schneider J, Knapp M, Beecham J, Netten A. Elderly people with dementia: costs, effectiveness and balance of care. In: Knapp M, ed. The economic evaluation of mental health care. Aldershot: Ashgate, 1995:125-56.

8 Alzheimer's Disease Society. The Alzheimer's disease report. Caring for dementia: today and tomorrow. Alzheimer's disease society, 2nd ed London:

9 Care of elderly people. Market survey 1995. 8th ed. London: Laing and Buisson, 1995

10 Bosanquet $\mathrm{N}$. The fourth age in the third millennium. Paper to Brendoncare Foundation Conference. Financial issues in choice and care. London: Brendoncare Foundation, February 6, 1995.

11 Philp I, McKee KJ, Meldrum P, Ballinger BR, Gilhooly MLM, Gordon DS, et al. Community care for demented and non-demented elderly people: a comparison study of financial burden, service use, and unmet needs in family support. BMF 1995;310:1504-6.

12 Glennerster H, Matsaganis M. The English and Swedish health care reforms. London: London School of Economics, health care reforms. London: London School
Nov 1992:41. (Discussion Paper WSP/79.)

13 Department of Health. Key indicators of local authority social separtment of Health. Key indicators of local author

14 Ferrario E, et al. Assessing dementia in day hospital: clinical, functional and social issues. Archives of Gerontology and Geriatrics 1991;(suppl 2):71-4

15 NHS Executive. Burdens of disease: a discussion document. Leeds: Department of Health, 1996.

16 Ostbye T, Crosse E. Net economic costs of dementia in Canada. Can Med Assoc F 1994;151:1457-9.

17 Gray A, Fenn P. Alzheimer's disease: the burden of the illness in England. Health Trends 1993;25:31-7.

18 Davies LM, Drummond MF. The economic burden of schizophrenia. Psychiatr Bull 1990;14:522-5.

19 Office of Health Economics. Arthritis. London: OHE, March 1992.

20 Ofice of Health Economics. Epilepsy. London: OHE, May 1992.

$21 \mathrm{Hu} \mathrm{T}$, Huang L, Cartwright WS. Evaluation of the costs of caring for the senile demented elderly: a pilot study. Gerontologist 1986;26:158-63.

22 Schulenburg JM, Horn R, Grobe-Einsler R, Bernhardt T, Muller HJ, Schulenburg. Kostenanalyse der Behandlung hirnleistungsgesturter Patienten Juli 1994. Geriat Forsch 1995;5:31-40.

23 Trabucchi A, Bianchetti A, Ghisla KM. Codem: a longitudinal study on Alzheimer's disease (AD) costs. Presented at tho nal study on Alzheimer's disease (AD) costs. Presented at the
Fourth International Nice/Springfield Symposium on Adrances In Alzheimer Therapv; 1996.

24 Haffenden S. Getting it right for carers. London: Department of Health Social Services Inspectorate, Department of Health, Her Majesty's Stationary Office, 1991

25 Glenndinning $C$. The costs of informal care: looking inside the household. London: HMSO, 1992.

26 Brodaty $\mathrm{H}$, Gresham $\mathrm{M}$. Effect of a training programme to reduce stress in carers of patients with dementia. BMF 1989;299:1375-9.

27 Williams O, Keady J, Nolan M. Younger-onset Alzheimer's disease: learning from the experience of one spouse carer. fournal of Clinical Nursing 1995;4:31 6.

28 Hervy $\mathrm{M}$, Comte $\mathrm{J}$, in association with France Alzheimer. Enquete nationale aupres de familles ayant en charge un parent atteint de maladie d'Alzheimer ou de troubles apparentes. Paris: France Alzheimer, 1995.

29 Department of Health. Caring for people. Community care in the next decade and beyond. London: HMSO, 1989

30 Cambridge and Huntington Health Commission. NHS responsibilities for meeting continuing health care needs. responsibilities for meeting

31 Baumgarten $M$. The health of persons giving care to the demented elderly: a critical review of the literature. $f$ Clin Epidemiol 1989;42:1137-48.

32 Clipp EC, George LK. Psychotropic drug use among care givers of patients with dementia. $\mathcal{F}$ Am Geriatr Soc 1990;38 227-35.

33 Jones DA, Peters TJ. Caring for elderly dependents: effects on the carers' quality of life. $A g_{\mathcal{C}}$ Aging 1992;21:421-8.

34 Brighter futures. Kidlington, Oxon: The Anchor Housing Association.

35 McWalter GJ, Toner HL, Eastwood J, Corser AS, Marshall MT, Turvey AA, Howie C. CarenapD: user manual for the
care needs assessment pack for dementia. Stirling: Dementia Services Development Centre, University of Stirling, May 1996.

36 Garner P, Godel M. Specialized early care for Alzhcimer's (SPECAL): making a present of the past. Oxford: Oxfordshire Mental Healthcare NHS Trust, 1996.

37 The Paignton and Brixham GP project. Torquav, Devon: South Devon Carers Consortium, Start date: April 1996.

38 Carers health project. Carshalton, Surrey: Merton and Sutton Community NHS Trust, Start date: March 1997.

39 Training and liaison for carers and care workers. Maidstone: Preston Hall Hospital, Start date: September 1994.

40 Crewkern carer project. Crewkerne: Crewkerne Health Centre, Start date: June 1996.

41 Bridgwater Carers Support Scheme. Bridgwater, Somerset: East Quay Medical Practice, Start date: November 1996.

42 Jackson LD. The role of medications in treating the behavioural disturbances of dementia sufferers. Perspectives 1995 19:9-22.

43 Devanand DP, Levy S R. Neuroleptic treatment of agitation and pychosis in dementia. $\mathcal{F}$ Geriatr Psychiatry Neurol 1995; 8:818-27.

44 Rogers S, Friedhoff LT, and Donepezil Study Group. The efficacy and safety of donepezil in patients with Alzheimer's disease: results of a US multicentre, randomised, doubleblind, placebo-controlled trial. Dementia 1996;7:293-303.

45 European Conference on Alzheimer's Disease and Related Disorders. Limerick, Ireland: Nov 20-2, 1996

46 Illiffe S, Mitchley S, Gould M, Haines A. Evaluation of the use of brief screening instruments for dementia, depression and problem drinking among elderly people in general practice. Br f Gen Pract 1994;44:503-7.

47 Folstein MF, Folstein SE, McHugh PR. Mini-mental state: a practical method for grading the cognitive state of a practical method for grading the cognitive state of
patients for the clinician. IPsychiatr Res 1975;12:189-98.

48 Muligan R, Mackinnon A, Jorm AF, Giannakopoulos P, Michel JP. A comparison of alternative methods of screening for dementia in clinical settings. Arch Neurol 1996;53 $532-6$

49 Friedhoff LT, Rogers SL. Donepezil lengthens time to loss of activities of daily living in patients with mild to moderate Alzheimer's disease: results of a preliminary evaluation [abstract]. Boston, USA: Annual Meeting of the American Neurology Academy, 12-19 April 1997

50 Keen J. Dementia. London: Office of Health Economics, September 1992:82.

51 Mundell I. Is tacrine worth the price? Inpharma 1993;910: 3-4.

52 Lubeck DP, Mazonson PD, Bowe T. Potential effect of tacrine on expenditures for Alzheimer's disease. Medical Interface 1994;7:130-8. 